\title{
TOURISM COMMUNICATION IN INDONESIA SOCIAL MEDIA
}

(Case Study of Melaka Tourism Communication through Social Media to Create Emotional Branding for Prospective Travelers)

\section{KOMUNIKASI PARIWISATA MELAKA MELALUI MEDIA SOSIAL}

(Studi Kasus Komunikasi Wisata Melaka Melalui Media Sosial Untuk Menciptakan Emotional Branding Calon Wisatawan)

\author{
Nela Widiastuti
}

Universitas Ars

Email: widiastutinela@yahoo.co.id

\section{How to Cite :}

Widiastuti, N. (2020). Komunikasi pariwisata melaka melalui media sosial (Studi Kasus Komunikasi

Wisata Melaka Melalui Media Sosial Untuk Menciptakan Emotional Branding Calon

Wisatawan). SENGKUNI Journal- Social Sciences and Humanities. DOI:

https://doi.org/10.37638/sengkuni.1.1.30-36
This is an open access article under the $\underline{C-B Y-S A}$ license

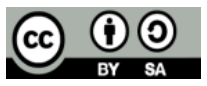

\section{ABSTRAK}

Melaka dikenal memiliki nilai-nilai historisnya, bahkan awal kelahiran Malaysia berawal dari negeri ini. Melaka juga dikenal sebagai pusat perdagangan maritim utama di kawasan ini tepatnya pada abad ke-16. Pedagang dari berbagai negara seperti Arab, Tiongkok, India dan Eropa juga datang ke Malaka untuk berdagang sutra, rempah-rempah, emas dan porselen. Oleh sebab itu pada 7 Juli 2008 UNECSO memberikan pengakuan kepada Melaka sebagai Negara Kota Warisan Dunia bersamaan dengan Georgetown, Negara Bagian Penang. Kini, Melaka hadir untuk menawarkan berbagai produk pariwisata berdasarkan 13 Sub-Sektor Produk Pariwisata, diantaranya Sejarah, Budaya, Rekreasi, Olahraga, Belanja, Konvensi, Kesehatan, Pendidikan, Agrowisata, Kuliner, Melaka Rumah Keduaku, Pariwisata Pemuda dan Ekowisata. Dengan mengusung tema "Melawat Melaka Bersejarah Berarti Melawat Malaysia" dan "Melaka Bandaraya Warisan Dunia Melaka UNESCO" Melaka menawarkan beragam keunikan budaya seperti budaya Melayu, Tiongkok, India, Portugis, Peranakan, Chitti dan lain-lain. Untuk lebih meningkatkan industri pariwisata Melaka, Pemerintah Negara Bagian Melaka mengambil inisiatif untuk meluncurkan Visit Melaka Year 2019 (VMY 2019) yang bertujuan untuk menampilkan kebudayaan dan keunikan Melaka lewat "Melaka A Gateway to Historic Malaysia". Penelitian ini mengeksplorasi tentang bentuk komunikasi pariwisata dalam Program Visit Melaka Year 2019 yang dicanangkan oleh pemerintah, Malaysia, dengan studi kasus pada wisatawan. Penelitian ini menggunakan pendekatan kualitatif dengan metode studi kasus. Pengumpulan data penelitian menggunakan metode wawancara, observasi terlibat dan studi pustaka. Tujuan penelitian ini adalah untuk mengetahui efektifitas strategi komunikasi pariwisata Melaka yang dicanangkan pemerintah, melalui sejumlah saluran komunikasi salah satu diantaranya melalui media sosial. Hasil penelitian menunjukkan bahwa media sosial memiliki peranan yang signifikan dalam menciptakan pengalaman emosional mengenai tempat wisata yang mereka kunjungi.

ABSTRACT 


\begin{abstract}
Melaka is known to have historical values, even the beginning of the birth of Malaysia began in this country. Melaka is also known as the main maritime trade center in this region precisely in the 16th century. Traders from various countries such as Arab, China, India and Europe also came to Malacca to trade silk, spices, gold and porcelain. Therefore on July 7, 2008 UNECSO recognized Melaka as a World Heritage City State together with Georgetown, the State of Penang. Now, Melaka is here to offer a variety of tourism products based on 13 Tourism Product Sub-Sectors, including History, Culture, Recreation, Sports, Shopping, Conventions, Health, Education, Agro Tourism, Culinary, Melaka My Second House, Youth Tourism and Ecotourism. With the theme "Touring Historical Melaka Means Visiting Malaysia" and "Melaka Bandaraya Melaka UNESCO World Heritage" Melaka offers a variety of cultural uniqueness such as Malay, Chinese, Indian, Portuguese, Peranakan, Chitti and others. To further enhance the Melaka tourism industry, the Melaka State Government took the initiative to launch Visit Melaka Year 2019 (VMY 2019) which aims to showcase the culture and uniqueness of Melaka through "Melaka A Gateway to Historic Malaysia". This research explores forms of tourism communication in the 2019 Melaka Visit Program launched by the government, Malaysia, with a case study on tourists. This research uses a qualitative approach with a case study method. Research data collection using interview methods, involved observation and literature study. The purpose of this study was to determine the effectiveness of the Melaka tourism communication strategy launched by the government, through a number of communication channels, one of them through social media. The results showed that social media has a significant role in creating emotional experiences about the tourist attractions they visit.
\end{abstract}

\title{
PENDAHULUAN
}

Selama ini Melaka dikenal memiliki nilai-nilai historisnya, bahkan awal kelahiran Malaysia berawal dari negeri ini. Melaka juga dikenal sebagai pusat perdagangan maritim utama di kawasan ini tepatnya pada abad ke-16. Pedagang dari berbagai negara seperti Arab, Tiongkok, India dan Eropa juga datang ke Melaka untuk berdagang sutra, rempah-rempah, emas dan porselen. Oleh sebab itu pada 7 Juli 2008 UNECSO memberikan pengakuan kepada Melaka sebagai Negara Kota Warisan Dunia bersamaan dengan Georgetown, Negara Bagian Penang.

Kini, Melaka hadir untuk menawarkan berbagai produk pariwisata berdasarkan 13 Sub-Sektor Produk Pariwisata, diantaranya Sejarah, Budaya, Rekreasi, Olahraga, Belanja, Konvensi, Kesehatan, Pendidikan, Agrowisata, Kuliner, Melaka Rumah Keduaku, Pariwisata Pemuda dan Ekowisata. Dengan mengusung tema "Melawat Melaka Bersejarah Berarti Melawat Malaysia" dan "Melaka Bandaraya Warisan Dunia Melaka UNESCO" Melaka menawarkan beragam keunikan budaya seperti budaya Melayu, Tiongkok, India, Portugis, Peranakan, Chitti dan lain-lain.

Untuk lebih meningkatkan industri pariwisata Melaka, Pemerintah Negara Bagian Melaka mengambil inisiatif untuk meluncurkan Visit Melaka Year 2019 (VMY 2019) yang bertujuan untuk menampilkan kebudayaan dan keunikan Melaka lewat "Melaka $A$ Gateway to Historic Malaysia". Acara yang digelar sepanjang tahun 2019 ini akan dimeriahkan oleh berbagai festival setiap generasi, termasuk diantaranya beragam festival budaya bertaraf internasional, acara yang berkonsep pada 13 Sub-Sektor Pariwisata Negeri Melaka serta kegiatan seni, pameran musik, promosi makanan khas, hiburan serta rekreasi dengan berbagai tema. Visit Melaka Year 2019 juga melibatkan dukungan dari berbagai pihak supaya membuat Melaka lebih kompetitif dan menjadi kontributor utama pembangunan sosial dan ekonomi Negeri Melaka.Kini Malaysia Tourism Board khususnya Dinas Pariwisata dan Kebudayaan Melaka lebih giat ber promosi pada turis Indonesia. Salah satunya melalui media sosial yang memiliki peran 
yang sangat besar dalam mengenalkan daerah wisata baru kepada khalayak sehingga menarik minat wisatawan untuk berkunjung.

Sebagai buah dari kehadiran internet sebagai media komunikasi, media sosial telah mengubah cara pemerintah, pihak swasta maupun individu untuk berkomunikasi dengan khalayak dan menyampaikan informasi kepada khalayak terkait dengan potensi wisata yang ada. Selain itu, tidak sedikit para wisatawan yang membagi pengalamannya berwisata di Malaka melalui media sosial seperti blog, Facebook. Instagram, Twitter, dan lain-lain. Media sosial juga digunakan oleh mereka yang berkecimpung di industri pariwisata sebagai lanskap pemasaran.

Hasil studi yang dilakukan oleh Kim, Fesenmaier, dan Johnson (2013) menyatakan bahwa platform media sosial seperti Facebook berpotensi besar memberikan efek yang sangat signifikan bagi persepsi dan emosi wisatawan selama melakukan perjalannan wisata dan karenanya dapat membuat pengalaman berwisata menjadi lebih berwarna. Pengalaman inilah yang dapat dibagi oleh wisatawan melalui berbagai platform media sosial yang dimiliki kepada orang lain. Secara tidak langsung, wisatawan tersebut membatu mempromosikan daerah wisata yang baru dikunjunginya.

Media sosial juga dapat dimanfaatkan untuk membentuk branding destinasi wisata. Dalam arti mengenalkan daerah-daerah yang berpotensi menjadi destinasi wisata kepada khalayak. Branding ini bisa disebut juga dengan identitas daerah wisata yang disajikan melalui nama, logo, warna, ataupun tag line. Kelebihan media sosial untuk meningkatkan brand awareness destinasi wisata adalah mengenalkan destinasi wisata agar dapat dengan mudah dicari orang yang gemar atau aktif di dunia maya. Dengan membentuk branding destinasi wisata diharapkan dapat membuat pengguna media sosial yang menjadi pengikut memperoleh informasi terbaru mengenai berbagai destinasi wisata yang ada. Selain itu, pembentukan branding ditujukan juga untuk menjangkau khalayak yang lebih luas lagi. Salah satu pengaruh media sosial adalah berkomunikasi dari mulut ke mulut namun secara daring. Sekecil apapun informasi yang disampaikan atau dipublikasikan di media sosial dapat segera tersebar luas. Dalam hal ini, media sosial memberikan kemudahan bagi setiap orang untuk menyebarkan informasi tentang daerah wisata atau potensi wisata yang ada kepada khalayak luas dengan cara mendorong orang untuk menyukai halaman media sosial atau membagi konten kepada orang lain.

\section{METODE PENELITIAN}

Penelitian ini menggunakan metodologi kualitatif deskriptif dengan metode studi kasus. Pendekatan kualitatif dipilih karena penelitian ini melibatkan emosi, harapan, keinginan, pemikiran subjek penelitian yang diwujudkan dalam bentuk perilaku, digali secara mendalam dan menyeluruh tetapi tidak untuk digeneralisasi. Mc.Millan dan Schumacher dalam Syaodih (2009:12) menyatakan bahwa penelitian kualitatif mempunyai dua tujuan yaitu menggambarkan dan mengungkap (to describe and explore) dan menggambarkan dan menjelaskan (to describe and explain). Sedangkan Jane Richie dalam Moleong (2010:6) mengemukakan bahwa penelitian kualitatif adalah upaya untuk menyajikan dunia sosial dan perspektifnya di dalam dunia, dari segi konsep, perilaku, persepsi dan persoalan tentang manusia yang diteliti.

Metode studi kasus digunakan karena keunikan dari masalah yang sedang diteliti, yaitu Komunikasi pariwisata Melaka mealui media sosial dalam menciptakan emotional branding. Studi kasus sendiri merupakan metode yang meneliti suatu peristiwa, program, proses atau kegiatan yang terjadi secara khusus yang 
menggambarkan kasus disebuah tempat dalam waktu dan periode tertentu. Studi kasus juga menjelaskan keunikan sebuah kasus yang terjadi di suatu tempat dan menarik karena kekhususannya. Penelitian studi kasus dibedakan menjadi tiga tipe yaitu eksplanatoris, eksploratoris dan deskriptif. Penelitian ini merupakan studi kasus dengan tipe deskriptif yaitu menggambarkan bagaimana konten dalam media sosial dapat menciptakan keterikatan emotional antara calon wisatawan dengan tempat wisata yang akan mereka akan kunjungi.

Pengumpulan data penelitian menggunakan metode survei, observasi dan studi pustaka. Wawancara dilakukan terhadap wisatawan yang menggunakan media sosial sebagai sumber referensi tujuan wisata mereka. Tujuan penelitian ini adalah untuk mengetahui efektifitas media ssoial dalam menciptakan emotional branding dalam diri calon wisatawan .

\section{HASIL DAN PEMBAHASAN}

Dalam melakukan promosi pariwisata diperlukan komunikasi. Dimana komunikasi harus memiliki minimal 3 unsur agar suatu komunikasi dapat berlangsung dengan baik. 3 unsur yang harus ada dalam sebuah kegiatan komunikasi yaitu : adanya komunikator sebagai pemberi informasi, adanya pesan yang disampaikan dan adanya komunikan sebagai penerima informasi. Selain 3 unsur tersebut, harus terdapat alat (instrumen) sebagai media perantara pemberi pesan dari komunikator kepada komunikan. Pentingnya komunikasi untuk komunikasi pariwisata adalah bagaimana seorang komunikator menggunakan teknik komunikasi yang efektif, sehingga pesan dapat tersampaikan dan ada feedback. komunikasi pariwisata merupakan suatu aktivitas manusia dalam menyampaikan informasi tentang perjalanan kesuatu daerah maupun objek wisata yang akan di kunjungi wisatawan sambil menikmati perjalanan dari suatu objek wisata ke objek wisata lainnya,agar wisatawan tertarik dan sampai pada suatu tindakan untuk mengunjungi.

Pengalaman membagi informasi melalui media sosial ini menjadi alat untuk melakukan kegiatan komunikasi dengan calon wisatawan yang pada akhirnya dapat membangkitkan minat dengan membentuk emotional branding dalam diri wisatawan sebagai konsumen. Emotional branding adalah sarana bagi konsumen dan brand dalam membangun hubungan secara tidak disadari. Hubungan antara konsumen dan brand terbentuk atau dibangun dengan menggunakan metode yang menggunakan faktor emosional. Dalam hal ini wisata Melaka sebagai brand dan wisatawan sebagai konsumen.

Berdasarkan Persentase, situs Web paling sering dikunjungi adalah Google. Halaman perusahaan raksasa internet ini hampir tiga kali lipat dari situs web di tempat ke-2 (Facebook) dalam hal kunjungan halaman. Di posisi nomor 3 ada Youtube yang menjadi mesin pencarian populer warga dunia maya. Ketiganya menjadi sumber utama dalam mencari infromasi salah satunya terkait dengan wisata. Pada saat mereka melihat gambar, tulisan dan menonton video, calon wisatawan tidak hanya mendapat sumber referensi terkait tentang tempat wisata yang akan mereka kunjungi namun juga mereka secara tidak langsung ikut merasakan pengalaman yang dibagikan oleh wisawatan lain yang pernah mengunjungi salah satu tempat wisata. Sehingga terciptalah emotional branding dalam diri calon wisatawan. 


\section{Percent of Most Visited Websites}

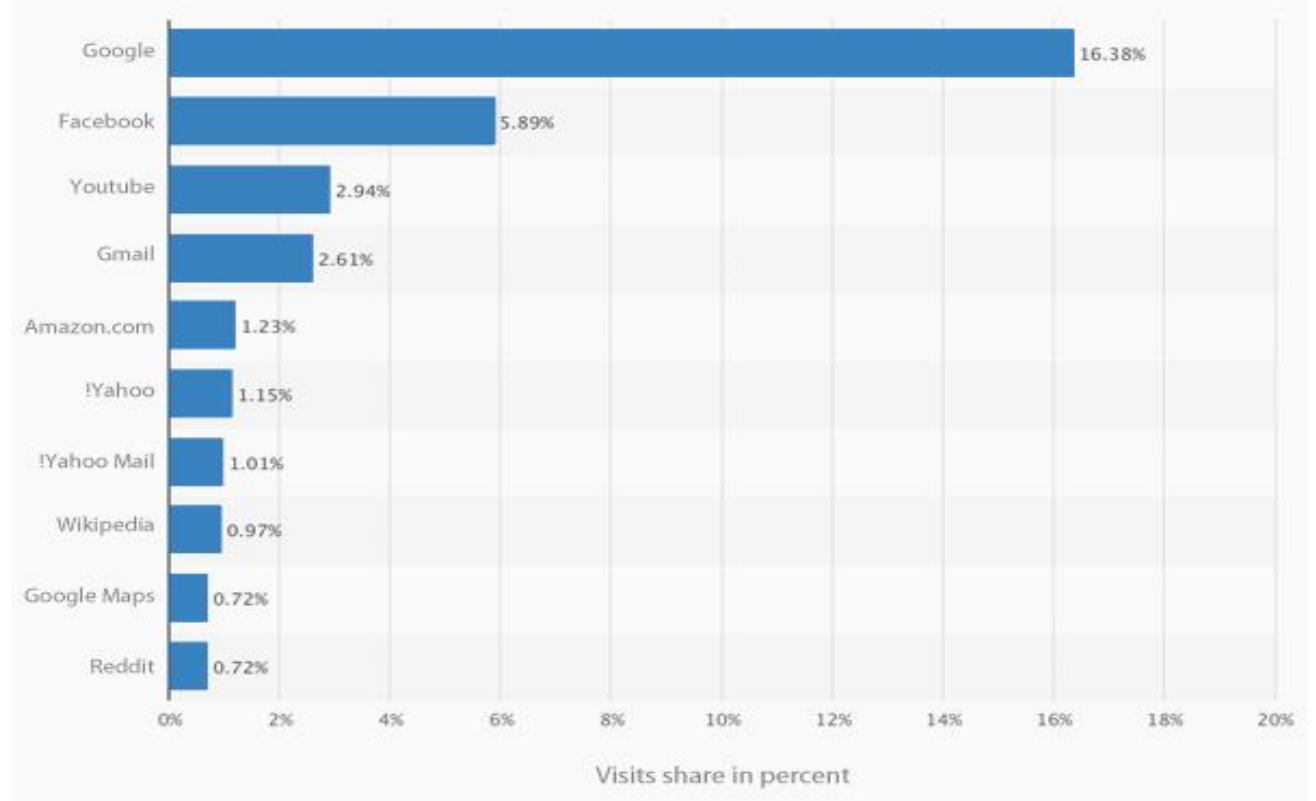

https://id.vpnmentor.com/blog/trend-internet-vital/

Emotional Branding berperan sebagai penentu kesuksesan sebuah brand dalam kompetisi pasar. Identitas sebuah brand dapat dibentuk dengan menghubungkan brand dan konsumen secara personal. Membangun emosi ini biasanya mengacu pada rasa percaya konsumen terhadap brand. Dengan kata lain, rasa percaya konsumen terbangun karena adanya keterlibatan emosi mereka dengan sebuah brand. Mereka membeli produk dari brand tertentu bukan semata-mata karena kebutuhan, tetapi transaksi yang dilakukan berdasarkan keinginan atau hasrat mereka.

Tujuan utama emotional branding yaitu membangun brand yang kuat dimata audiens dengan menciptakan branding yang mengacu pada pengalaman dan keinginan emosional konsumen secara mendalam. Selain membangun hubungan dengan pelanggan juga untuk memberikan nilai pada brand atau produk dalam jangka waktu panjang. Hal ini dilakukan dengan memberikan pengalaman indrawi dan dibuat agar customer merasakan keunggulan produk dan bersedia membeli. komunikasi adalah kunci untuk menciptakan emotional branding yang kuat. Investasi yang paling penting dalam mengembangkan suatu brand adalah membangun emosi konsumen. Strategi ini merupakan janji dan nilai yang diberikan kepada konsumen untuk menikmati brand tersebut dengan panca indra mereka.

Melaka sebagai brand pariwisata negara Malaysia menggunakan konsep emotional branding dalam menarik wisatawan mancanegara sebanyak mungkin. Diantaranya memaksimalkan konten yang ada di media sosial seperti facebook, 
youtube dan twitter. Sebagai contoh, pemerintah Malaysia bekerja sama dengan beberapa vlogger travel dari berbagai dunia untuk mempromosikan daerah pariwisata yang ada di Melaka melalui saluran youtube mereka. Menurut sebuah studi, $45 \%$ dari image sebuah brand berasal dari apa yang mereka katakan dan bagaimana mereka mengatakannya. Hal ini mempengaruhi perasaan orang, emosi mereka, sikap dan opini terhadap sebuah brand. Gambar yang eye-catching dan menarik juga menjadi cara memanfaatkan visual marketing. $63 \%$ dari semua konten media sosial adalah gambar, ini menjadi peuang besar untuk membentuk emotional branding Melaka di dalam diri netizen.

Berdasarkan dari pengamatan peneliti dari lama Youtube tercatat lebih dari 300 video yang membahas tentang wisata di kota Melaka oleh berbagai vloger dari berbagai negara. Respon dari atau komentar yang diberikan penonton, menunjukkan adanya minat dan ketertarikan dari penonton untuk datang berkunjung ke kota Melaka. Mereka merasa senang dan takjub setelah menonton video di youtube tentang Melaka padahal sebelumnya mereka belum pernah datang ke Melaka.

Hasil survei menyatakan bahwa kebanyakan wisatawan tidak menggunakan agen travel. Sebanyak $72 \%$ responden mengatakan mereka mengumpulkan informasi wisata dari Instagram. Sebanyak $62 \%$ wisatawan millenial mencari referensi dari Youtube dan $40 \%$ lainnya dari Facebook. Separuh responden menyimpan informasi terkait wisatanya dalam bentuk digital. Sebagai tambahan, 47\% responden sering membagikan informasi wisata dengan orang lain di media sosial atau aplikasi chatting, hanya $18 \%$ yang membagikan informasi wisata saat bertemu tatap muka. Hasil survei tersebut menunjukkan peran penting media sosial bagi kebutuhan wisatawan millenial. Mayoritas responden cenderung membagikan pengalaman wisatanya di media sosial. Untuk kegiatan travelling berikutnya, mereka lebih suka mencari cara yang paling efisien untuk mengakses informasi di internet, disamping lebih mudah dan murah mereka dapat melihat bagaimana keindahan dari tempat pariwisata yang akan mereka tuju, disinilah emotional branding tercipta.

\section{KESIMPULAN}

Jika saat ini media cetak mulai ditinggalkan, sementara iklan di televisi cenderung akan dilewatkan oleh penonton, maka kita harus dapat melakukan komunikasi merek dengan cara yang dikemas secara lebih menarik dan mengena. Promosi wisata yang dilakukan tidak hanya berbentuk pameran atau festival budaya yang diselenggarakan di dalam negeri melainkan juga di luar negeri. Namun juga dapat memanfaatkan media sosial secara maksimal. Peran media seperti media massa dan media sosial juga sangat besar dalam mengenalkan daerah wisata baru kepada khalayak sehingga menarik minat wisatawan untuk berkunjung. Sebagai buah dari kehadiran internet sebagai media komunikasi, media sosial telah mengubah cara pemerintah, pihak swasta maupun individu untuk berkomunikasi dengan khalayak dan menyampaikan informasi kepada khalayak terkait dengan potensi wisata yang ada. Selain itu, tidak sedikit para wisatawan yang membagi pengalamannya berwisata di Indonesia melalui media sosial seperti blog, Facebook. Instagram, Twitter, dan lain-lain. Komunikasi yang baik dan menarik melalui media sosial akan disimak secara langsung oleh netizen dan mereka dapat dengan cepat segera membandingkan keunggulan dan kekurangan suatu merek dengan merek lain, kemudian mengambil keputusan akan menggunakan merek tersebut atau tidak. Dengan kata lain, komunikasi pariwisata yang baik dan menarik di media sosial menjadi faktor penentu lainnya yang menentukan apakah calon wisatawan akan datang ke tempat wisata tersebut atau tidak. 


\section{DAFTAR PUSTAKA}

Cohen,E. A Phenomenology of Tourist Experiences. Journal of British sociological Association.1979

Gobe, Marc. Emotional Branding. 2003. Erlangga. Jakarta.

Jeongmie Kim, Daniel R. Feseinmaier, Steven L. Johnson. Journal : The Effect of Feedback within Social Media in Tourism Experiences. Juni 2013

LexyJ.Moleong.(2011). Metodelogi peneltian kualitatif. Bandung. PT Remaja Rosdakarya

Travel.kompas.com

www.malacca.ws

https://id.vpnmentor.com/blog/trend-internet-vital/ 